\title{
Burn All Your Textbooks
}

\author{
Varol Akman \\ Department of Computer Engineering \\ Bilkent University \\ Bilkent, Ankara 06800, Turkey
}

\begin{abstract}
The standard propositional exposition of necessary and sufficient conditions, as available in introductory logic texts, leads to a contradiction. It should be abolished.
\end{abstract}

Keywords: Necessary condition, sufficient condition, neither-nor

The standard propositional account of necessary and sufficient conditions in many introductory logic textbooks is based on the material conditional. Some examples include (Barker-Plummer, Barwise, and Etchemendy 2011: 181-182), (Churchill 1986: 391-392), (Forbes 1994: 20-25), (Gabbay 2002: 68), (Haight 1999: 187-189), (Halverson 1984: 285286), (Hardegree 2011: 129), (Layman 2002: 250-251), (Leblanc and Wisdom 1976: 16-18), (Salmon 1984: 47-48), (P. Smith 2003: 132), (Suppes 1957: 8-10) and (Watson and Arp 2015: 149). In the appendix, pertinent excerpts from some of these resources are provided. In general, the typical exposition goes along the following lines (again, cf. the appendix):

- " $A$ is sufficient for $B$ " is best rendered as "if $A$, then $B$ ", or symbolically, $(A \supset B)$.

- " $A$ is necessary for $B$ " is best rendered as "if not $A$, then not $B$ ", or symbolically, $(\neg A \supset \neg B)$. This is equivalent to $(B \supset A)$.

We can then combine these to obtain " $A$ is necessary and sufficient for $B$ ", viz. $((B)$ $A) \wedge(A \supset B))$. Using the material biconditional, it is seen that $A$ is necessary and sufficient for $B$ just when $A$ if and only if $B$, or symbolically, $(A \equiv B)$. This is all very good, even beautiful in its simplicity.

But now suppose, as any curious beginner might - and at some point, should - suggest, that we would like to see what " $A$ is neither necessary nor sufficient for $B$ " amounts to. Since this is equivalent to " $A$ is not necessary for $B$ " combined with " $A$ is not sufficient for $B$ ", we obtain:

$$
(\neg(B \supset A) \wedge \neg(A \supset B)),
$$

or, equivalently, $\neg((B \supset A) \vee(A \supset B))$. But this is a contradiction in classical logic. 
Our novice does a little search on the internet to ascertain that it is perfectly all right for a proposition to be neither necessary nor sufficient for another. In other words, there is no contradiction in the notion of "being neither necessary nor sufficient". The following are titles of some scientific articles (these can be easily converted into a form so that "neither necessary nor sufficient" is flanked by propositions):

- Monocular symmetry is neither necessary nor sufficient for the dichoptic perception of bilateral symmetry. ${ }^{1}$

- Hydrogen peroxide from the oxidative burst is neither necessary nor sufficient for hypersensitive cell death induction ...2

- Basic fibroblast growth factor is neither necessary nor sufficient for the development of retinal neovascularization. ${ }^{3}$

In conclusion, one may demand that the classical exposition of necessary and sufficient conditions be abolished from introductory textbooks, for it only confuses the beginner. It is wiser to postpone the study of these conditions to a more advanced medium which does justice to their complexity, e.g., one where a modal framework is on offer (Hardegree, in progress). For starters, it is possible to deal with these conditions in first order logic, as reported in (N. Smith 2012: 181). The trick is to see $A$ and $B$ as one-place predicates, not as propositions. Thus, Smith says that " $A$ is a sufficient condition for $B$ " means that having the property $A$ is enough for something to have the property $B$ and should be rendered $\forall x(A x \supset B x)$. Likewise " $A$ is a necessary condition for $B$ " means that nothings possesses the property $B$ if it does not possess the property $A$ and should be rendered $\forall x(B x \supset A x)$. Then " $A$ is neither sufficient nor necessary for $B$ " comes out as $\neg(\forall x(A x \supset B x) \vee \forall x(B x \supset A x))$ which is not a contradiction.

\section{Appendix}

Here we give five examples of the standard exposition of necessary and sufficient conditions. The authors have been arbitrarily chosen from the references.

\section{Excerpt from Churchill 1986, pp. 391-392}

A necessary condition, $\mathrm{N}$, for a specified effect, $\mathrm{E}$, is a condition without which $\mathrm{E}$ cannot occur.

This definition can be expressed in the following conditional statement:

If not- $N$, then not- $E$.

\footnotetext{
${ }^{1}$ Wenderoth 2000

${ }^{2}$ Dorey, et al. 1999

${ }^{3}$ Ozaki, et al. 1998
}

Australasian Journal of Logic (14:3) 2017, Article no. 2 
In truth-functional symbolism, this becomes

$$
\sim N \supset \sim E
$$

$[\ldots]$

A sufficient condition, $S$, for the occurrence of a specific effect, $E$, is a condition such that if $S$ occurs, then $E$ must also occur. This definition can also be expressed as a truth-functional conditional:

$$
S \supset E .
$$

Excerpt from Layman 2002, p. 251

A sufficient condition is a condition that guarantees that a statement is true (or that a phenomenon will occur). For instance, Fidos being a dog guarantees that he is an animal. By contrast, Fidos being an animal does not guarantee that he is a dog, for he might be some other kind of animal. The antecedent (if-clause) of a true conditional statement provides a sufficient condition for the truth of the consequent (then-clause).

A necessary condition is a condition that, if lacking, guarantees that a statement is false (or that a phenomenon will not occur). Thus, Fidos being an animal is a necessary condition for Fidos being a dog, for if Fido is not an animal, then he is not a dog. The consequent (then-clause) of a true conditional statement provides a necessary condition for the truth of the antecedent (if-clause).

\section{Excerpt from Leblanc and Wisdom 1976, pp. 16-17}

A statement $A$ (or its truth) is sometimes said to be a sufficient condition for (the truth of) a statement $B$ if $A \supset B$ is true; and a statement $A$ is said to be a necessary condition for a statement $B$ if $\sim A \supset \sim B$, and hence $B \supset A$, is true.

\section{Excerpt from Salmon 1984, p. 47}

To say that a condition is necessary for a result means that the result will not occur if the condition is not fulfilled. When " $p$ " constitutes a necessary condition for " $q$ " we may symbolize the situation by " $\sim p \supset \sim q$," which, as we know, is equivalent to " $q \supset p$.

$[\ldots]$

To say that " $p$ " constitutes a sufficient condition for " $q$ " means merely that " $q$ " will obtain if " $p$ " does - in other words, it means simply " $p \supset q$. ."

\subsection{Excerpt from Suppes 1957, p. 8}

As a matter of notation, the conditional sentence formed from any two sentences $P$ and $Q$ is written

$$
P \rightarrow Q
$$

Australasian Journal of Logic (14:3) 2017, Article no. 2 
The sign ' $\rightarrow$ ' is often called the sign of implication. Several other idioms of English have approximately the same systematic meaning as 'if, then'. We shall also write $P \rightarrow Q$, for

$P$ only if $Q$

$Q$ if $P$

$Q$ provided that $P$

$P$ is a sufficient condition for $Q$

$Q$ is a necessary condition for $P$.

\section{References}

Barker-Plummer, D., Barwise, J. and Etchemendy, J. 2011. Language, Proof and Logic (2nd edition). Stanford, CA: CSLI Publications.

Churchill, R. P. 1986. Becoming Logical: An Introduction to Logic. New York: St. Martins Press.

Dorey, S., Kopp, M., Geoffroy, P., Fritig, B., and Kauffmann, S. 1999. Hydrogen Peroxide from the Oxidative Burst Is Neither Necessary Nor Sufficient for Hypersensitive Cell Death Induction, Phenylalanine Ammonia Lyase Stimulation, Salicylic Acid Accumulation, or Scopoletin Consumption in Cultured Tobacco Cells Treated with Elicitin Plant Physiology 121: $163-171$.

Forbes, G. 1994. Modern Logic: A Text in Elementary Symbolic Logic. New York: Oxford University Press.

Gabbay, M. 2002. Logic with Added Reasoning. Peterborough, ON: Broadview Press.

Haight, M. 1999. The Snake and the Fox: An Introduction to Logic. London: Routledge.

Halverson, W. H. 1984. A Concise Logic. New York: Random House.

Hardegree, G. 2011. Symbolic Logic: A First Course (4th edition). New York: McGrawHill. Old edition available at http://courses.umass.edu/phil110-gmh/MAIN/IHome-5.htm

Hardegree, G. in progress. Introduction to Modal Logic. Available at http://courses.umass.edu/phil511gmh/text.htm

Layman, C. S. 2002. The Power of Logic (2nd edition). New York: McGraw-Hill.

Leblanc, H. and Wisdom, W. A. 1976. Deductive Logic (2nd edition). Boston: Allyn and Bacon.

Ozaki, H., Okamoto, N., Ortega, S., Chang, M., Ozaki, K., Sadda, S., Vinores M.A., Derevjanik, N., Zack, D.J., Basilico, C., and Campochiaro, P.A. 1998. Basic fibroblast growth 
factor is neither necessary nor sufficient for the development of retinal neovascularization American Journal of Pathology 153: 757-765

Salmon, W. C. 1984. Logic (3rd edition). Englewood Cliffs, NJ: Prentice-Hall.

Smith, N. J. J. 2012. Logic: The Laws of Truth. Princeton, NJ: Princeton University Press.

Smith, P. 2003. An Introduction to Formal Logic. Cambridge, UK: Cambridge University Press.

Suppes, P. 1957. Introduction to Logic (5th printing). Princeton, NJ: D. Van Nostrand.

Watson, J.C. and Arp, R. 2015. Critical Thinking: An Introduction to Reasoning Well (2nd edition). London: Bloomsbury Academic.

Wenderoth, P. 2000. Monocular symmetry is neither necessary nor sufficient for the dichoptic perception of bilateral symmetry Vision Research 40: 2097-2100

Australasian Journal of Logic (14:3) 2017, Article no. 2 